\title{
РОЛЬ ГОСУДАРСТВА В ФОРМИРОВАНИИ АДАПТИВНОЙ ЭФФЕКТИВНОСТИ РОССИЙСКОЙ ЭКОНОМИЧЕСКОЙ СИСТЕМЫ
}

Аннотация. Опыт разных стран показывает, что в один и тот же исторический период национальные экономики могут существенно отличаться по параметрам адаптивной эффективности. При ее рассмотрении на макроуровне объективно встает вопрос о движущих силах, стимулах и механизмах, которые реально способствуют или могли бы способствовать продвижению национальных экономик в плане повышения уровня этой эффективности. С позиций неоклассической школы любые движущие силы в экономике, стимулы и механизмы ее развития постепенно (эволюционным путем) формируются, прежде всего, самим рынком. Соответственно и формирование параметров адаптивной эффективности не может обеспечиваться иначе как на основе рыночного механизма, который в силу самой своей природы приучает людей оценивать и взвешивать последствия своих действий с учетом постоянной неопределенности и изменчивости широкого круга параметров окружающего мира, т. е. заставляет их стремиться к преодолению неопределенности через рациональное поведение и в текущий момент и на перспективу. Безусловно, у рынка в плане адаптации людей к неопределенности очень много заслуг. Вместе с тем, как известно, рыночный механизм не только не в состоянии избавлять людей от неопределенности, но и даже, как уже отмечалось, способствует росту этой неопределенности по целому ряду направлений.

Ключевые слова. Специфичность активов, адаптивная эффективность, диверсификация экономики, структурная трансформация экономики. 
Abstract. The experience of different countries shows that at the same historic period national economies can differ significantly from each other in terms of adaptive efficiency. While studying this type of efficiency at macro level the researchers inevitably come across with such issues as its driving forces, stimuli and mechanisms that promote or could promote national economies by increasing this efficiency. From the perspective of Neoclassical school any driving forces, stimuli and mechanisms in the economy are being developed gradually (evolutionary) by the market itself. Thus, parameters of adaptive efficiency are formed by the market mechanism. This mechanism naturally makes people asses and weigh the consequences of their actions taking into consideration constant uncertainty and instability of different environment parameters. In other words, the market mechanism stimulates people to overcome uncertainty through rational behavior both currently and prospectively. Undoubtedly, the market has a lot of merits in adapting people to uncertainty. But at the same time, as it is known, the market mechanism is not able to get people out of uncertainty; moreover, this mechanism can even increase uncertainty in different directions.

Keywords. Assets specificity, adaptive efficiency, economic diversification, structural transformation of economy.

Адаптивную макроэкономическую эффективность можно системно рассматривать через адаптивное инвестиционное равновесие, а ее уровень оценить через тезаврационные процессы в сфере сбережений. Однако, на наш взгляд, тут возникает закономерный вопрос: насколько достижение критериев адаптивной эффективности Д. Норта (конкуренция, децентрали- 
зация и защита прав собственности) являются достаточными с позиции факторов, обеспечивающих рост адаптивной эффективности. Или другой - возможно ли повысить адаптивную эффективность в случае низкой конкурентной среды (как, например, в России) и что для этого необходимо.

Как нам представляется, базовым показателем адаптивной эффективности следует принимать скорость (или саму возможность) перехода потенциального излишка в категорию допустимого к извлечению, а из нее в извлекаемый излишек. При этом особая роль должна отводиться спецификации активов и инвестиций $[7$, с. 27-32].

И если на микроуровне под спецификацией активов (инвестиций) традиционно понимаются капиталовложения экономических субъектов, то на макроуровне мы можем расширить этот подход. В этом случае предполагается более широкая трактовка, а под спецификацией можно подразумевать отраслевые изменения, например, в виде дифференциации и расширения в пользу наиболее перспективных направлений экономики.

Особую важность этому вопросу придает тот факт, что низкая степень адаптивной эффективности в России «блокирует» процессы, необходимые и для экономического роста, и для самого существования независимой экономики.

Действительно, согласно данным статистики, с одной стороны мы видим некий прирост объема выпуска в обрабатывающем сегменте на 0,1\% в 2016 г. Однако, с другой, место России в международном разделении труда все больше закрепляется за ресурсоориентированным сегментом.

Минеральное сырье в 2016 г. составляло 59,2\% от всего экспорта. Также углубляется разрыв между инвестициями - в 2014 г. от всех инвестиций в основной капитал 15,1\% шло в обрабатывающий сектор и 15,5\% в 
добывающий, а в 2016 г. по указанным сегментам 14,6\% и 19,4\% соответственно.

Несомненно, это отразилось и на физическом объеме инвестиций. Если в добывающей промышленности прирост инвестиций в 2016 г. по сравнению с 2015 г. составил 14,4\%, то в обрабатывающей произошло их падение на $10 \%$.

При этом следует учитывать, что указанные капиталовложения не покрывают даже потребность в индуцированных инвестициях и не обеспечивают простого воспроизводства (табл. 1).

Казалась бы в сложившейся ситуации бессмысленно и несколько наивно рассуждать о необходимости повышения степени спецификации активов. Однако, если адаптивная эффективность в целом обеспечивает эволюцию всей системы во времени, то проявлением ее основного критерия (трансформации излишков) будет активизация в современной экономике таких явлений как инновации, модернизация, дифференциация и т. д. Все это требует повышенного степени общественного разделения труда, что достигается углублением специфичности активов.

Таблица 1

Состояние основных фондов в российской промышленности

\begin{tabular}{|l|c|c|c|c|}
\hline Показатель & 2010 & 2014 & 2015 & 2016 \\
\hline $\begin{array}{l}\text { Степень износа основных } \\
\text { фондов, \% }\end{array}$ & 45,7 & 47,9 & 48,8 & 50,2 \\
\hline $\begin{array}{l}\text { Износ основных фондов в сфере } \\
\text { добычи полезных ископаемых, \% }\end{array}$ & 46,8 & 53,0 & 52,8 & 54,9 \\
\hline $\begin{array}{l}\text { Износ основных фондов в сфере } \\
\text { обрабатывающего производства, \% }\end{array}$ & 42,2 & 44,7 & 45,9 & 47,4 \\
\hline
\end{tabular}

Источник ${ }^{1}$

1 Российский статистический ежегодник. 2017. URL: http:/ / www.gks.ru/bgd/regl/b17_13/Main.htm.

2017. T. 18, № 4. C. 736-757 


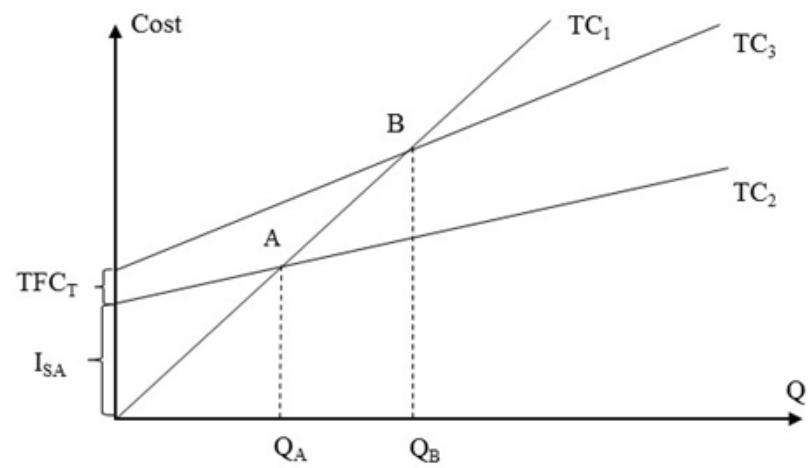

Рис. 1. Формирование издержек при спецификации активов (инвестииий)

В самой природе специфичных активов наблюдается определенное противоречие. С одной стороны, специфичные ресурсы служат источником повышения конкурентоспособности, а с другой, обладание подобными ресурсами, в связи с действием фактора неопределенности может привести к экономическим убыткам.

Следовательно, для выявления факторов, влияющих на адаптивную эффективность, стоит рассмотреть сам процесс принятия бизнесом решений о повышении специфичности активов (рис. 1)

На представленном рисунке отражены общие производственные издержки на производство блага с использованием двух условных видов активов - общих $\left(\mathrm{TC}_{1}\right)$ и специфических $\left(\mathrm{TC}_{2}\right)$ в условиях нулевой неопределенности, которые можно отразить в следующих формулах:

$\mathrm{TC}_{1}=\mathrm{Q} \times \mathrm{k} 1$, где

k1 - средние переменные издержки использования неспецифичных активов.

$\mathrm{TC}_{2}=\mathrm{I}_{\mathrm{SA}}+\mathrm{Q} \times \mathrm{k} 2$, где

$\mathrm{I}_{\mathrm{SA}}-$ технологические капиталовложения в дополнительную спецификацию активов; 
k2 - средние переменные издержки использования специфичных активов.

В данном случае k1 и k2 выступают в роли технологических коэффициентов, отражающих производительность и формирование уровня переменных издержек соответствующими активами.

До точки $A$ (объем производства $Q_{A}$ ), где издержки $\mathrm{TC}_{1}$ и $\mathrm{TC}_{2}$ уравновешиваются, предпринимателю более выгодным является производство с низкой степенью спецификации активов.

Введения фактора не нейтральных институтов и неопределенности формирует новую кривую издержек производства с учетом спецификации активов $\mathrm{TC}_{3}$ :

$$
\mathrm{TC}_{3}=\mathrm{TC}_{2}+\mathrm{TFC}_{\mathrm{T}}+\mathrm{Q} \times \mathrm{k} 3 \text {, где }
$$

$\mathrm{TFC}_{\mathrm{T}}$ - единовременные трансакционные издержки на спецификацию активов;

k3 - средние переменные трансакционные издержки использования специфичных активов.

В виду того, что решение предпринимателем принимается исходя из будущего состояния квазиренты, k3 - во многом субъективный параметр, в который заложено восприятие бизнесом неопределенности, по сути он отражает эффективность институтов, в т. ч. их способность снижать вторичную неопределенность. Чем хуже институты и выше неопределенность, тем больше $\mathrm{k} 3$ и тем круче угол наклона $\mathrm{TC}_{3}$. В абстрактной ситуации идеальных институтов $\mathrm{k} 3=0$, а при полном отсутствии институтов (хаос) $\mathrm{k} 3 \rightarrow \infty$. Таким образом k3 - не обязательно фактический уровень затрат, а скорее «ожидания» со стороны бизнеса трансакционных издержек вследствие несовершенства институтов.

При введении обозначения общих инвестиций по дополнительной спецификации активов:

$$
\mathrm{I}=\mathrm{I}_{\mathrm{SA}}+\mathrm{TFC}_{\mathrm{T}}
$$

Мы сможем показать тот необходимый объем производства $\mathrm{Q}_{\mathrm{B}}$ (точка $B$ где соблюдается равенство 2017. T. 18, № 4. C. 736-757 
$\mathrm{TC}_{1}=\mathrm{TC}_{3}$ ) ниже которого стратегия «переключения» на специфичные активы нецелесообразна для бизнеса следующим образом:

$$
\mathrm{Q}=\frac{\mathrm{I}}{\mathrm{k} 1-\mathrm{k} 2-\mathrm{k} 3}
$$

Сама стратегия переключения возможна только при соблюдении двух основных условий:

Во-первых, если:

$\mathrm{k} 1>\mathrm{k} 2+\mathrm{k} 3$

Если это условие не соблюдается, то мы будем наблюдать ситуацию, когда высокий уровень неопределенности блокирует возможность присвоения части квазиренты бизнесом (т. е. $\mathrm{TC}_{1}<\mathrm{TC}_{3}$ при любых значениях Q).

Во-вторых, если:

$\mathrm{Q}_{\mathrm{B}} \leq \mathrm{Q}_{\mathrm{d}}$, где

$\mathrm{Q}_{\mathrm{d}}$ - ожидаемый бизнесом эффективный спрос.

Учитывая разделение излишков на разные категории, можно сказать, что логика стратегии переключения на специфичные ресурсы выглядит следующим образом: до достижения объема $\mathrm{Q}_{\mathrm{A}}$ в системе существует только потенциальный излишек. В промежутке от $\mathrm{Q}_{\mathrm{A}}$ и до $\mathrm{Q}_{\mathrm{B}}$ излишек переходит в категорию допустимого к извлечению. И только если система поддерживает спрос выше $\mathrm{Q}_{\text {в }}$ излишек становится извлекаемым с позиции бизнеса (в виде присвоения квазиренты).

Ввиду того, что планирование и, соответственно, ожидания эффективного спроса зачастую формируются более чем на 1 период, сам объем эффективного спроса с точки зрения бизнеса необходимо рассматривать с учетом 2 факторов развития - горизонта планирования и темпов экономического роста. Подобный подход весьма часто используется современными исследователями. Так, например, Е. В. Балацкий, анализируя целый ряд экономических явлений (выход из институциональных и технологических ловушек, тех- 
нологические рывки, инновационное развитие и т. д.) особо отмечает в своих моделях, что «горизонт планирования является ведущим фактором технологической и институциональной эволюции», а его снижение может быть компенсировано только возрастанием темпов экономического роста и наоборот. [2, с. 58]

Если ввести упрощенное допущение, что темпы прироста спроса постоянны, то сам объем ожидаемого предпринимателями спроса будет рассчитываться следующим образом:

$$
\begin{aligned}
& \mathrm{Q}_{\mathrm{d}}=\sum^{t} \mathrm{Q} \times(1+\mathrm{T})^{\mathrm{n}} \text {, при } \mathrm{n}=1 . . \mathrm{t}, \text { где } \\
& \mathrm{T}-\text { ожидаемый темп прироста спроса; } \\
& \mathrm{t} \text { - горизонт планирования. }
\end{aligned}
$$

Вводя временной фактор, необходимо также предусмотреть капитализацию общих инвестиций по дополнительной спецификации активов, что позволит учесть альтернативную норму дохода (i) до момента их окупаемости. Учитывая изложенное, саму стратегию переключения на специфичные инвестиции можно формализовать следующим образом:

$$
\frac{\mathrm{I} \times(1+\mathrm{i})}{\mathrm{k} 1-\mathrm{k} 2-\mathrm{k} 3} \leq \sum^{t} \mathrm{Q} \times(1+\mathrm{T})^{\mathrm{n}} \text {, при } \mathrm{k} 1>\mathrm{k} 2+\mathrm{k} 3
$$

Таким образом, допустимо, как нам кажется, сделать следующий вывод - все факторы, уменьшающие левую и / или увеличивающие правую часть уравнения ведут к росту адаптивной эффективности, что способствует возникновению более качественной структуры экономики.

Рассматривая представленные в уравнении агрегаты, на наш взгляд можно выделить тот минимальный набор факторов, без которых переключение на специфические активы (соответственно, и достижение адаптивной эффективности) представляется маловероятным: 
- $k 2$ зависит от качества и развития человеческого капитала, без которого использование специфических активов невозможно;

- $k 3$ зависит от уровня неопределенности и, следовательно, от качества институциональной среды;

- $t$ также зависит от институциональных факторов (качества среды, защиты прав собственности, уровня доверия и т. д.) и от доступности ресурсов во времени (например, длительного кредитования);

- $i$ формируется в своей основе денежно-кредитной политикой;

- Т изменяется за счет колебаний немонетарных факторов спроса;

- I зависит как от институциональных факторов (в части $\mathrm{TFC}_{\mathrm{T}}$ ), так и от цены капитала.

С учетом изложенного показательным представляется анализ точки зрения, что в России в момент кризиса 2014-2015 годов были созданы благоприятные условия для модернизации и диверсификации экономики. Напомним, что подобная точка зрения базируется на двух основных моментах:

Во-первых, падение цен на ресурсы выступает в качестве шока, создающего повышенную мотивацию к структурной трансформации.

Во-вторых, санкции и контрсанкции ограничили давление импорта, что повысило эффективный спрос на товары отечественного производства.

Анализируя представленную модель, на наш взгляд, можно сказать, что эта точка зрения несколько не соответствует действительности. Рассмотрим как изменились агрегаты, используемые при анализе стратегии переключения на специфичные инвестиции:

Большинство технологий, необходимых для структурной трансформации российские предприятия могут пока приобрести только за рубежом. Падение национальной валюты и санкции привели к увеличению агрегата $I$. 
Рост неопределенности экономической ситуации в стране в 2015 - 2016 гг. по сравнению с 2014 г. привел к росту $k 3$ и падению $t$.

Ужесточение денежно-кредитной политики значительно увеличивает $i$.

Планируемое секвестирование бюджета и отказ от индексирования социальных трансфертов по уровню инфляции уменьшает ожидания бизнеса по агрегату $T$.

Как мы видим, происходит не увеличение, а общее снижение спроса по внутренним секторам обрабатывающей промышленности и услуг в российской экономике.

К тому же не стоит забывать, что нашим западным партнерам, когда дело касается национальных интересов, свойственно «забывать» о рыночных принципах и «равноправной» конкуренции. Так, например, в феврале 2016 г. в связи с новообразованными курсовыми (валютными) «преимуществами» российских металлургов, ЕС выставил временные «антидемпинговые» пошлины на холоднокатаный прокат в 26 \%. При этом следует учитывать, что объемы российского экспорта только по квадратным заготовкам арматуры оцениваются в 718 тыс. тонн в год. ${ }^{1}$

Таким образом мы наблюдаем рост левой части уравнения при падении правой, что никак нельзя назвать стимулирующим воздействием на экономику ни с позиций структурной трансформации, ни с позиций достаточной адаптивной эффективности. Очевидно, подобное состояние можно трактовать и как «провал стихийного рынка» с позиций формирования траектории устойчивого развития.

Как мы видим, разработка методологии адаптивной эффективности предполагает выявление также

${ }^{1}$ Европа грозит России арматурой // Коммерсант. 2016. 25 февр. - URL : http://kommersant.ru/doc/2923517. 
других, альтернативных рынку вариантов «движущей силы» формирования и совершенствования элементов этой эффективности. Поиск этих вариантов, как представляется, опять заставляет обратиться к институциональному направлению исследований в экономической теории, хотя бы потому, что после кейнсианства институционализм, не умаляя известных заслуг рынка в качестве регулятора в экономике и обществе, тем не менее наиболее четко признает его ограниченность и возможность фиаско по целому ряду направлений в данной функции. Кроме того, именно институционализм подчеркивает, что экономика в любом обществе не является самостоятельной и главной его сутью, а выступает лишь как одна из его подсистем. Именно общество (а не сама по себе экономика) «устанавливает права собственности, определяет базовую структуру стимулов экономической системы», именно общество «контролирует соблюдение этих прав», так что именно решения, принимаемые в рамках общества (а, следовательно, и прежде всего политического процесса) «оказывают влияние на функционирование экономики» [6, с. 142-144], и в любом обществе функционирует не экономический, а неразрывный политико-экономический процесс. Отсюда одним из наиболее важных принципиальных выводов институционального направления является положение Д. Норта о том, что отнюдь не рынок правит современной экономикой, a, напротив, «в современном мире самым главным детерминантом функционирования экономики выступают доля ВНП, проходящая через руки государства, и всепроникающая, постоянно меняющаяся система государственного регулирования». [2, с. 143]

Данная идея Норта развивается и комментируется во многих трудах представителей институционального направления. Например, Э. Фуруботн и Р. Рихтер, критически оценивая возможности полной экономической свободы рыночных субъектов в условиях вы- 
сокого уровня неопределенности, подчеркивают, что «при децентрализованной деятельности в ситуации несовершенной информации эффективная аллокация ресурсов не может быть достигнута, если не вмешается государство и не введет целый набор субсидий и налогов». [8, с. 584]

Несмотря на то, что идеи о необходимости активизировать роль государства в экономике известны уже более 3/4 века, неоклассическая школа, как известно, либо в силу своей объективной ограниченности, либо из своей политической миссии неизменно стоит на позициях рыночного либерализма. Вторая возможная причина кажется все более убедительной, учитывая в каких масштабах идет перекачка доходов между странами.

Так как официальная наука (мейнстирм) направляется теми странами, которые живут за счет не только собственных экономик, но и перераспределения в свою пользу доходов других стран, даже самых отсталых и слаборазвитых, то представляется, что именно для них (т. е. обираемых стран) постоянно идут рекомендации о необходимости всяческого устранения государства от управления экономикой (ведь иначе процесс перераспределения (изъятия) чужих доходов в свою пользу существенно усложнится). К сожалению, на особо благодатную почву такие рекомендации легли в странах, входивших ранее в социалистическую систему. Недостатки установившихся моделей централизованного управления и догматизм мышления руководителей с успехом подавались как доказательство общей порочности государственного присутствия в экономике в принципе. В результате, поддавшись на ультра-рыночные реформы, эти страны поспешили совсем убрать централизованные начала в управлении экономикой. Между тем, сама жизнь показывает, что гораздо больших успехов в формировании элементов адаптивной эффективности добились те страны, кото2017. T. 18 , № 4. C. $736-757$ 
рые фактически признали ведущую роль государства в экономике.

Имеется в виду, что либеральное направление в современной экономической теории и политике постоянно провозглашает необходимость «освобождение» бизнеса от «диктата» и «указаний» государства, история большинства современных развитых и развивающихся стран с достаточной очевидностью доказывает, что своими успехами в деле формирования новой структуры экономики и новых моделей и механизмов макроэкономического хозяйствования, соответствующих требованиям инновационной экономики XXI в., они в большей мере, чем стихийным рынкам обязаны своим государствам, т. к. либо прошли определенные периоды реального жесткого государственного регулирования важнейших параметров своих экономик, либо находятся в стадии такого достаточно ощутимого государственного воздействия и по настоящее время.

Общепризнанными считаются в этом плане пути и способы достижения необходимых структурных сдвигов и буквально волевого перевода экономик на интенсификацию в таких странах, как Корея и Китай. Однако не стоит забывать, что элементы жестких нерыночных способов государственного воздействия на структуру экономики неоднократно наблюдались во Франции, США, Германии, Японии, Сингапуре, Малайзии и многих других странах.

Не случайно в этой связи, по мнению многих исследователей, в XX и XXI веке роль государства в управлении экономикой не только не снижается, но фактически устойчиво присутствует и на уровне предприятий, и на макроуровнях большинства стран. Экономика практически любых стран является на протяжении вот уже более века фактически либо активно регулируемой государственными органами (как, например, в рамках Евросоюза), либо вообще управляется государством (при некотором расширении рыночных начал), 
как, например, в Китае. Такие оценки происходящего фактического усиления роли государств большинства стран в макрорегулировании и макроконтроле привели (в частности в России) к формированию в последние годы нового направления в экономических исследованиях - а именно к теории управляемой экономики. Как отмечает один из лидеров этого направления П. Лабзунов, «заметно усиливается роль государственного управления с 30-х годов XX века в Европе, Америке, Азии, практически на всех континентах: достаточно указать на тотальное регулирование в Евросоюзе от уровня дефицита бюджетов, состояния банков или финансовую помощь из госказны США бизнесу и населению; Евросоюз во многом вообще является калькой СССР». [4, с. 15]

Представляется, что на позициях «управляемой экономики» находится также и широкий круг авторов, исследующих серьезные изменения роли современного государства в регулировании национальных экономик, происходящие внутри отдельных стран и в системе международного разделения труда вследствие формирования глобальной экономики. Эти авторы за основу исследований берут такую новую реальность мира как растущая экономическая открытость стран и такие новые черты мировой экономики, обуславливающие ее современную значимость для всех стран, как формирование фактически всемирной информационной сети, обеспечивающей все более широкое взаимодействие всех стран в режиме реального времени, усиливающееся действия ТНК как глобальных экономических агентов, формирование глобального финансового рынка как главного элемента глобальной финансовой системы, происходящую либерализацию национальных режимов торговли и капиталопотоков и т. П.

В результате ни одна страна не может уже эффективно развиваться, не взаимодействуя на постоянной 2017. T. 18 , № 4. C. $736-757$ 
основе с внешним рынком и новой экономической инфраструктурой. Соответственно, разные страны вынуждены наряду со своими традиционными функциями выполнять в качестве все более важных (а нередко и первоочередных) различные функции, обеспечивающие данные постоянные взаимодействия с внешней средой.

Весьма характерными, на наш взгляд, являются в этой связи те новые стратегически важные функции экономической политики современных государств, которые выделяются сторонниками данного рода исследований. В качестве первой (и, следовательно, стратегически наиболее важной) выделяется функция старта новой экономики. Выделение этой функции как первоочередной объясняется природой новых технологий, которые буквально созидают эту экономику и выступают теперь как главные факторы развития во многих странах.

Поскольку главным достижением и содержанием новой экономики является, как известно, формирование всемирной информационной сети (далее - ВИС), то хотелось бы еще раз кратко напомнить, как возникла эта ВИС.

Ведущую роль в создании ВИС и ее постоянном расширении, а также в усилении ее влияния в мире играют, как известно, США. Эта страна взяла на себя роль информационно-технологического гегемона в ВИС не только благодаря своим огромным возможностям в плане организации и обеспечения НИОКР, но и в силу того, что мотивы государства в США в области экономической политики и их особо высокие потребности в непрерывных инновациях давно уже с военными стратегиями. Сама ВИС их особо интересует в плане возможностей совершенствования и исполнения этих стратегий. Соответственно, именно США,

${ }^{2}$ На США приходится почти половина общемировых расходов на НИОКР.

2017, vol. 18, no. 4 , pp. $736-757$ 
начиная с создания своей уникальной «силиконовой долины», объединяющей широкий круг наукоемких производств, во-первых, обеспечивает ускоренное развитие целого ряда специфических отраслей новой экономики. Во-вторых, смогли добиться эффективного функционального взаимодействия их важнейших направлений, т. е. таких достижений науки и технологий, как микроэлектроника, телекоммуникации, оптическая электроника, компьютеры, Интернет (которые в совокупности и составляют ВИС).

Будучи созданной, ВИС, как известно, выступает одновременно не только результатом, но и предпосылкой для осуществления в «автоматическом режиме» целого ряда глубоких качественных изменений в структуре экономики развитых стран, наиболее активно опирающихся на эту сеть. Так, благодаря ВИС чрезвычайно ускоряется процесс перехода от капиталоемких отраслей к наукоемким, углубляя процессы международной специализации и кооперации производства, усиливая тенденции к «деиндустрализации» различных экономик, к развитию образования, науки, средств связи, телекоммуникаций. Кроме того, для «подпитки» ВИС необходимы огромные потоки информации, в результате чего большая часть ВВП в развитых странах обеспечивается деятельностью, связанной с производством, обработкой, хранением и распространением информации. С этой целью в развитых странах существует широкий круг структур, занимающихся сертификацией, сбором и распространением информации, необходимой как для совершения рыночных сделок, так и для целей анализа различных тенденций в развитии мировых рынков и стратегически важных отраслей, обеспечения пополнения глобальных хранилищ знаний, имеющих ценность для многих миллионов людей. Не удивительно в этой связи, что по некоторым оценкам, затраты на информацию, прямо или косвенно связанную с 2017. T. 18 , № 4. C. $736-757$ 
ВИС, уже к началу XXI века составляли в некоторых странах $3 / 4$ добавленной стоимости всей продукции [5, с. 150] и что до 80 \% роста ВВП в этих странах достигается за счет инновационного сектора, включая ВИС. [1, с. 28]

Пример США (в плане выполнения государством функции старта новой экономики) был, как известно, использован некоторыми другими странами, государства которых стали стимулировать создание внутринациональных информационных сетей и их взаимодействие с ВИС. При этом каждая страна решала проблему обеспечения своего участия в ВИС по-своему, опираясь на свои отработанные способы решения важных макроэкономических задач. КНР, например, начала процесс создания своей национальной информационной системы с разработки в 1990-х гг. специальной «Программы инновации знаний» (ее обкатка началась с 1997 г. в г. Лючоу, а с 2002 г. От уровня эксперимента был сделан переход к общей и обычной практике действий). Государство КНР прежде всего обеспечило всеобщую правительственную поддержку НИОКР, связанных с переносом технологий инновации знаний и их распространении. В качестве первого шага была организована ощутимая поддержка самому динамичному сектору тайваньской промышленности в виде клонированного производства персональных компьютеров. Государство начало оказывать помощь этому сектору еще в 1960-х гг., теперь же в рамках разработки программы, правительство приобрело лицензию на технологию проектирования чипов вместе с обучением китайских инженеров американской компанией. В последующем, опираясь на этих инженеров, правительство создало государственный исследовательский центр, работу которого старалось обеспечивать на уровне последних достижений мировой электронной технологии с упором на ее коммерческое применение. По указанию правительства, этот центр организовал 
семинары предприятиям, чтобы бесплатно распространять технологию ВИС, которую оно создавала среди тайваньских мелких фирм. Кроме того, инженеров центра поощряли оставлять институт после нескольких лет работы в нем и обеспечивали им правительственное финансирование и технологическую поддержку, чтобы они могли начать свой собственный международный бизнес.

Таким образом, между правительством и деловыми сетями было построено продуктивное взаимодействие: сети оставались относительно маленькими, а правительственная политика брала на себя координацию и функции стратегического планирования, когда таким сетям было необходимо расширить и улучшить охват и диапазон своей деятельности в производстве и на рынках, связанных со структурой ВИС. Был построен ряд институтов (Центр производительности, Торговый совет и др.) для распространения информации ВИС (о рынках, технологиях, менеджменте и других критически важных аспектах) через сети мелких предприятий. Таким образом, государство, совершенствуя координирующие и стратегические функции, обеспечило приобщение к возможностям ВИС широкого круга мелких предприятий, без чего они с их малыми «собственными» сетями никогда не были бы способны достичь рынка других стран. В результате китайские промышленники подобно Японии стали активно обзаводиться контактами с региональными сетями как внутри, так и вне страны. Учитывая усилия государств наиболее развивающихся стран в выполнении функции старта новой экономики, нельзя, на наш взгляд, не признать совершенно справедливой критику авторами тех государств, которые недооценивают роль и значимость этой новой функции. Эта недооценка, как полагают исследователи «способна создать угрозу исключения национальных и даже континентальных экономик (например, Африка) из мировой информа2017. T. 18 , № 4. C. $736-757$ 
ционной системы и, соответственно, из мировой системы разделения труда». [3, с. 53]

Второй важной новой стратегической функцией современных государств, с позиций рассматриваемого подхода, является функция инкорпорирования в процессе перестройки экономических институтов на региональном и страновом уровнях. Имеется в виду, что одной из характерных черт глобализации мировой экономики с присущими ей противоречиями и проблемами является стремление многих стран к формированию своеобразных регионов-квазифирм, исполняющих элементы общей внутренней и внешней политики для обеспечения общей устойчивости функционирования и развития в такие комплексы стран. Общеизвестно, что наряду с Евросоюзом, который наиболее продвинулся в формировании квазифирм, есть множество других, хотя и менее эффективных, но все же двигающихся по пути все большего инкорпорирования объединений стран.

В качестве третей рассматривается функция координации, т. е. функция поддержки государством внутри страны территориальной сети с тем, чтобы обеспечивался наивозможно больший синергетический эффект от разных передовых технологий, что очень важно для поддержания эффективной инновационной среды для поддержания отечественных предприятий.

Необходимость в данной функции объясняется тем, что развертывание различных новых технологий не всегда идет достаточно взаимосвязано, т. е. их сближение и взаимодействие может происходить медленно и далеко не в полном объеме. Соответственно, для получения сколько-нибудь ощутимых синергетических эффектов от различных новых технологий на макроуровне нужно определенным образом скоординировать не только значительные финансовые вливания, но и организационные усилия ряда различных структур. Устранить расхождения и противоречия в 
ведомственных интересах, обеспечить ускоренное взаимодействие новых технологий и распространение их как среди отечественных потребителей, так и на территориях других стран. Это, конечно, не означает, что государство обязательно полностью само осуществляет эту функцию. Оно может выделить для решения задач координации какую-либо наиболее успешно зарекомендовавшую себя в разработке и продвижении новых технологий частную компанию, предоставив ей и необходимое финансирование, и защиту (на первых порах) от нежелательных конкурентов, и правомочия по распространению полученных технологических открытий в отечественном общественном секторе и за рубежом. Так, правительство США в 70-х годах XX в., взяв на себя роль инициатора, финансиста и организатора развития и координирования новых технологий, обеспечивших формирование в стране информационно-технологической системы, фактически очень близко работало только с одной компанией - ATT.

\section{Єписок использованной литературы}

1. Балацкий Е. В. Инновационный сектор промышленности / Е. В. Балацкий, В. И. Лапин // Экономист. - 2004. № 1. - С. 20-33.

2. Балацкий Е. В. Институциональные и технологические ловушки: анализ идей / Е. В. Балацкий // Журнал экономической теории. - 2012. - № 2. - С. 48-63.

3. Кастельс М. Информационная эпоха: экономика, общество и культура. / М. Кастельс. - М. : ГУ ВШЭ. - 2000. - 458 с.

4. Лабзунов П. Выход из экономического кризиса - модель управляемой экономики / П. Лабзунов / / Инвестиции в России. - 2017. - № 3. - С. 12-17.

5. Львов Д. О. О прошлом и будущем России / Д. О. Львов // Вопросы экономики. - 2001. - № 10. - С. 146-150.

6. Норт Д. Институты, институциональные изменения и функционирование экономики / Д. Норт. - М. : Начала, 1997. - 180 с.

7. Рудяков В. А. Анализ и оценка эффективности адаптаций к неопределенности в российской экономике / В. А. Рудяков. - Иркутск : Изд-во БГУЭП, 2015. - 127 с. 
8. Фуруботн Э. Институты и экономическая теория: достижения новой институциональной экономической теории / Э. Фуруботн, Р. Рихтер. - СПб. : СПбГУ, 2005. - 702 с.

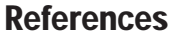

1. Balatsky E. V., Lapin V. I. Innovative industry. Ekonomist = The Economist, 2004, no. 1, pp. 20-33. (In Russian).

2. Balatsky E. V. Institutional and technological traps: analysis of ideas. Zhurnal ekonomicheskoi teorii $=$ Russian Journal of economic theory, 2012, no. 2, pp. 48-63. (In Russian).

3. Castells M. Informatsionnaya epokha: ekonomika, obshchestvo $i$ kul'tura [The Information age: economy, society and culture]. Moscow, GU VShE Publ., 2000. 458 p.

4. Labzunov P. Recovery from the economic crisis - a model of managed economy. Investitsii $v$ Rossii = Investment in Russia, 2017, no. 3, pp. 12-17. (In Russian).

5. Lvov D. O. About the past and future of Russia. Voprosy ekonomiki $=$ Questions of economy, 2001, no. 10, pp. 146-150. (In Russian).

6. Nort D. Instituty, institutsional'nye izmeneniya i funktsionirovanie ekonomiki [Institutions, institutional change and economic performance]. Moscow, Nachala Publ., 1997. 180 p.

7. Rudyakov V. A. Analiz i otsenka effektionosti adaptatsii $k$ neopredelennosti $v$ rossiiskoi ekonomike [Analysis and evaluation of the effectiveness of adaptations to uncertainty in the Russian economy]. Irkutsk, Baikal State University of Economics and Law Publ., 2015. 127 p.

8. Furubotn E., Richter R. Institutions and Economic Theory: The Contribution of the New Institutional Economics. The University of Michigan Press, 1998. 673 p. (Russ. ed.: Furubotn E., Richter R. Instituty i ekonomicheskaya teoriya: dostizheniya novoi institutsional'noi ekonomicheskoi teorii. Saint Petersburg State University Publ., 2005. 702 p.).

\section{Информация об авторе}

Рудяков Васииий Анатольевич - кандидат экономических наук, доцент, кафедра экономической теории и институциональной экономики, Байкальский государственный университет, 664003, РФ, г. Иркутск, ул. Ленина, 11, e-mail: fmened@mail.ru.

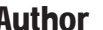

Vasiliy A.Rudyakov - PhDin Economics, AssociateProfessor, Chair of Economic Theory and Institutional Economics, 
Baikal State University, 11 Lenin St., 664003, Irkutsk, Russian Federation, e-mail: fmened@mail.ru.

\section{Для цитирования}

Рудяков В. А. Роль государства в формировании адаптивной эффективности российской экономической системы / В. А. Рудяков // Историко-экономические исследования. - 2017. - Т. 18, № 4. - С. 736-757. DOI: 10.17150/2308-2588.2017.18(4).736-757.

\section{$47: 4$.}

Rudyakov V. A. The Role of the State in Forming Adaptive Efficiency of the Russian Economic System. Istorikoekonomicheskie issledovaniya = Journal of Economic History $\mathcal{E}$ History of Economics, 2017, vol. 18, no. 4, pp. 736-757. DOI: 10.17150/2308-2588.2017.18(4).736-757. (In Russian). 